\title{
Strategic human resource management technology effect and implication for distance training and learning
}

\author{
Khalil Alsaadat \\ Department of Educational Policies, College of Education, King Saud University, Saudi Arabia
}

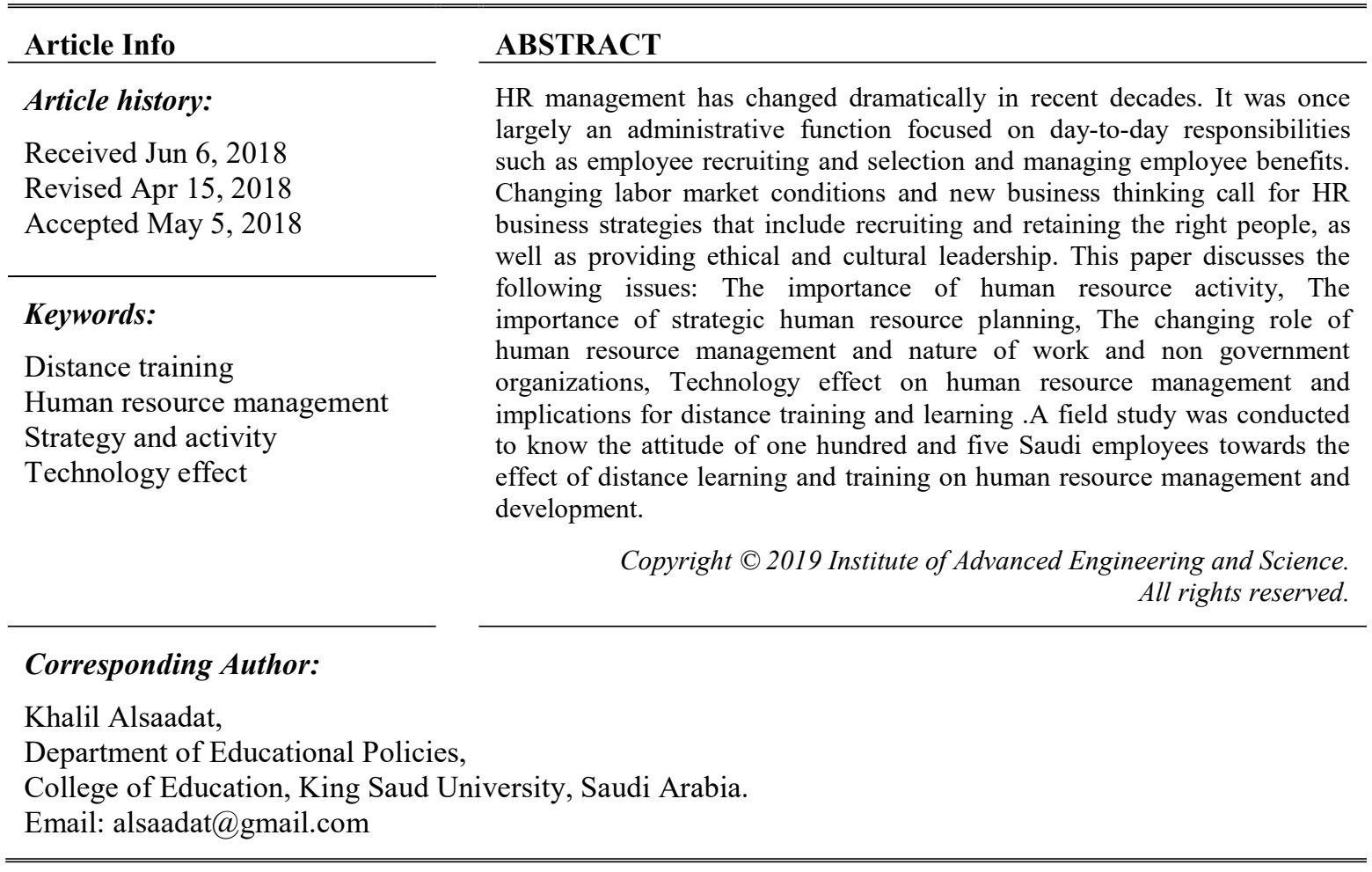

\section{INTRODUCTION}

HR management has changed dramatically in recent decades. It was once largely an administrative function focused on day-to-day responsibilities such as employee recruiting and selection and managing employee benefits. Changing labor market conditions and new business thinking call for HR business strategies that include recruiting and retaining the right people, as well as providing ethical and cultural leadership [1]. The field of human resource management has a long and rich tradition [2]. Strategic human resource management (SHRM) describes how HRM is aligned with strategic goals and objectives to enhance business performance and to develop organisational cultures that boost flexibility and innovation. The importance of SHRM is revealed by Darwish et al, who reported that the concept, during the past decade, has attracted a great deal of attention largely because of its potential impact on the functions of business organisations. This attention accorded SHRM is reflected in the growing importance of human capital and its role in gaining competitive advantage and improving organisational performance. HR activities such as recruitment, selection, training and rewarding personnel are done by keeping in view the company's goals and objectives, which are defined by strategies. Aligning HR activities with the strategic goals of firms has facilitated organisations to achieve superb targets. Nagaraj and Kamalanabhan reveal the need to have a link between strategic planning and HRM. By implication, HRM need to be approached from strategic point of view, which calls for a link between HRM practices and HR strategies [3].

An early and widely accepted definition of strategic HRM is 'the pattern of planned human resource deployments and activities intended to enable an organization to achieve its goal . The definition subsumes the notion of human resource bundles or configurations, as patterns of activities that develop over time that support successful adaptation and organizational performance. Less attention is paid to another strand of the 
strategic HRM research, which describes and analyzes the involvement of the HR function in the strategic management process. In this conception of strategic HRM, the term 'making HR more strategic' draws on Ulrich's early model of strategic HRM which posits that the way for the HR function to become more involved in the strategic process is for the HR function to change from being primarily an administrative expert to being a strategic business partner and supporting the strategic process [4].

This purpose of the study is to know the attitude of one hundred and five Saudi employees towards the effect of distance learning and training on human resource management and development. this would be integrated with discussion various issues such as the importance of human resource activity, The importance of strategic human resource planning, the changing role of human resource management and nature of work and non government organizations, technology effect on human resource management and implications for distance training and learning.

\section{RELATED WORKS}

Ericksen and Dyer studied the extended strategic human resource management (SHRM) thinking to theory and research on high reliability organizations (HROs) using a behavioural approach. After considering the viability of reliability as an organizational performance indicator, they identified a set of eight reliabilityoriented employee behaviours likely to foster organizational reliability and suggest that they are especially valuable to reliability-seeking organizations that operate under 'trying conditions'. They then developed a reliability-enhancing human resource strategy likely to facilitate the manifestation of these ROEBs. They concluded that the behavioural approach offers SHRM scholars an opportunity to explain how people contribute to specific organizational goals in specific contexts and, in turn, to identify human resource strategies that extend the general high performance human resource strategy (HPHRS) in new and important ways [5].

Kramar studied strategic human resource management (SHRM) emerged as a dominant approach to human resource management (HRM) policy during the past 30 years. However, during the last decade, a new approach to HRM has evolved. This approach has been labelled sustainable human resource management (sustainable HRM). It is an approach that seeks to link HRM and sustainability. The term sustainability is fraught with semantic difficulties, as is conceptualising its relationship to HRM. Consequently, sustainable HRM is viewed in a variety of ways. This study examines the major features of SHRM, some of the meanings given to sustainability and the relationship between sustainability and HRM. It then outlines the major characteristics of sustainable HRM. Although there are a diversity of views about sustainable HRM, this approach has a number of features which differentiate it from SHRM. It acknowledges organisational outcomes, which are broader than financial outcomes. All the writings emphasise the importance of human and social outcomes. In addition, it explicitly identifies the negative as well as the positive effects of HRM on a variety of stakeholders; it pays further attention to the processes associated with the implementation of HRM policies and acknowledges the tensions in reconciling competing organisational requirements. Such an approach takes an explicit moral position about the desired outcomes of organisational practices in the short term and the long term. Sustainable HRM can be understood in terms of a number of complimentary frameworks [6].

Amberg and Mcgaughy studied Corporate Entrepreneurship (CE) supports sustained competitive advantage through the continuous exploration and exploitation of new sources of knowledge. With an emphasis on combining knowledge in new configurations, strategic human resource management (HRM) activities are core to these entrepreneurial endeavours. Amberg and mcgaughy explored how strategic HRM activities may facilitate and impede CE through a rich, qualitative case study of three local entities within a business unit of a large multinational enterprise facing business stagnation and low levels of corporate entrepreneurship. Responding to a call for more empirical research that probes the subtle and complex interactions between HRM activities and other organisational factors affecting CE, they identified a configuration of inter dependent factors that mutually reinforce each other and sustain inertia in corporate entrepreneurship. They also make two novel contributions to theory by (1) elaborating the links between organisational process orientation, strategic $\mathrm{HRM}$ and $\mathrm{CE}$; and (2) refining to their current understanding of human competencies for CE [7].

Marler\&perry studied Associated with the emergence of internebased humanresource management technology is rhetoric predicting that such technological advances (electronic human resource management technology or e-HRM) will make HRM in organizations more strategic. Yet such a prediction is contested in the literature on the role of technology in organizations. Using a large survey data-set consisting of 5665 companies that are located in 32 different countries, the researchers use non-recursive simultaneous equation models with instrumental variables to empirically evaluate competing theoretical perspectives in this literature. They found and showed that strategic HR involvement and greater e-HRM capability are both

Strategic human resource management technology effect and implication for distance... (Khalil Alsaadat) 
directly and reciprocally related supporting both theoretical perspectives but also showing each is not mutually exclusive. They discussed the implication of these results for humanresource management theory, practice and future research [4].

Alfes et al studied there is an increasing interest from scholars and practitioners in understanding how nonprofit organizations can design and implement human resources (HR) practices to enhance desirable volunteer attitudes and behaviors. This study presents a comprehensive overview of existing studies on the relationship between HR practices and volunteering outcomes. They use the ability-motivation-opportunity model as a guiding framework to systematically integrate current knowledge on this topic. They identified gaps in existing research and offered detailed suggestions on how scholars can further enhance knowledge on how HR practices can lead to beneficial outcomes for both volunteers and non-profit organizations [8].

The previous studies showed that human Resource Development (HRD) operates within competitive global environments and the changing expectations of societal moral values, which can be in conflict with organizational values, performance, and profit. These are underpinned by the unquestioning acceptance and 'orthodoxy' of free-market economics, legalism, and codes of conduct that result in a lack of ethical analysis within HRD practice [9]. HR's role includes developing a plan of HR initiatives to achieve and promote the behaviors, culture and competencies needed to achieve organizational goals. Results oriented goals broadly include the following:

a. Correctly assessing staffing and skills needs and keeping training up-to-date.

b. Developing and maintaining competitive pay and benefits.

c. Managing performance and designing a rewards system that keeps employees motivated.

d. Knowing what competitors are doing to recruit and retain talent.

e. Providing training, including ethics, which reinforces corporate values [1].

\section{HUMAN RESOURCE MANAGEMENT}

\subsection{Importance of humn resource activity}

It is increasingly becoming evident that human resource (HR) practices impact on organisational performance and competitive advantage, and firms that experience these practices are those that employ good people management practices. HR has evolved and there has been a shift from the administrative role through to HR business partner role. HR now focuses more on value addition and need for aligning HR activities with strategic planning. This shift has been necessitated by the concept of human capital or human assets including skills, judgement and intelligence of a firm's employees. Relevance of this linkage becomes evident in the work of Thite, that the HR functions in organisations that emphasise human capital establish business partnership with line managers who have direct interest and involvement in delivering HR. The HR functionaries therefore become an integral part of the strategic business units and customise HR solutions to provide fast and efficient services [3].

Human Resource Management (HRM) is an important faction of management that deals with the most valuable assets of an organization which is human resources. The whole context of HRM is currently being considered in the light of sustainability all over [9].Shen, et al argued that human resource management is inherently a multilevel field of study. Complicated processes in the environment interact with organizational systems to affect outcomes at the firm, unit, and individual levels. HRM systems operate within complex organizational systems and structures that are further affected by macroeconomic forces and competitive forces that drive and alter implementation plans. These effects move through the layers of the organization to affect the performance of the firm. Simultaneously, these factors combine to affect microphenomenon like individual job performance, turnover, job satisfaction, and organizational commitment, creativity, and citizenship behaviors. In sum, processes and systems in HRM cut across strategic and operational levels to affect both macro- and micro-oriented outcome [10].

\subsection{The importance of strategic human resource planning}

The closer the alignment between HR and an organization's overall business strategy, the better the company's ability to anticipate and respond to customer needs and to maintain competitive advantage. Rigorous research, planning and development involving workforce culture, behaviors and competencies promote the successful execution of business strategy. Particular benefits of HR strategic planning include the following:

a. Avoiding costly and disruptive surprises that interfere with achieving goals.

b. Addressing key issues in a timely manner to avoid crises.

c. Promoting employee productivity and overall organizational success.

d. Providing a sense of direction to positively affect how work gets done.

e. Keeping employees focused on organizational goals. 
f. Providing a strategic focus to guide training and development initiatives.

g. Giving leaders tools to help focus and implement their strategic initiatives [1].

\subsection{The changing role of human resource management ADN nature of work}

Kowalski and loretto believe that Changing workplaces present new challenges to employees and employers alike as stakeholders attempt to navigate the introduction of new technologies amidst a dynamic business environment and while organisations seek to remain viable and to keep employees healthy and performing well. Changes are being seen in terms of who is working, where, when and how. Considerable changes have also been seen in where we work, particularly for knowledge workers who do already have greater flexibility in terms of where and when they work. The role of location has been of great interest to a number of scholars in this field, not only in terms of the effect on performance, but also due to the potential effects on worker well being. Kowalski and loretto also believe that the rise and rise of advances in communication technologies has facilitated this greater freedom of movement for workers. Another key shift that has been evident is the move away from permanent contracts and a shift towards less routine systems, such as temporary and zero hour contracts. Such changes are in parallel with the rise of the 'gig economy', which whilst potentially allowing greater flexibility for workers, also offers less security and has parallels with the 'precarious' work highlighted in the seminal work by Standing [11].

In light of the economic, social and political changes, the changing functions of $\mathrm{HR}$, and the changing role for HR practitioners is something that must be addressed explicitly in research into the relationship between HRM, employee well being and performance . Changes include a shift towards a more strategic role for HR practitioners, a trend towards outsourcing and outsourcing of the HR provision itself, greater opportunities for flexible working, managing a multi generational workforce and devolvement of some HR functions to line managers [11].Tylor and Finley added that a national trend in HR is to move from the administrative role to the incorporation of HR in strategic planning. This movement was aided by the development of the concept of human capital or human assets in an organization [12].

Collins and Smith developed and tested a theory of how human resource practices affect the organizational social climate conditions that facilitate knowledge exchange and combination and resultant firm performance. A field study of 136 technology companies showed that commitment-based human resource practices were positively related to the organizational social climates of trust, cooperation, and shared codes and language. In turn, these measures of a firm's social climate were related to the firm's capability to exchange and combine knowledge, a relationship that predicted firm revenue from new products and services and firm sales growth [13].

\subsection{Human resource management and non goernment organizations}

Bartram et al, discussed the role of non government organization with respect to human resource management they argued that In recent years, the role of HRM within the non-government organisation (NGO), volunteer and not-for-profit sector and its potential to positively contribute to volunteer well-being and build healthy communities has become topical among governments, management practitioners, scholars and communities across different national settings. The third sector is important to the welfare of many communities across all geographical levels from the local to the global. Consequently, throughout the world, efficient and effective management of NGO, volunteer and not-for-profit organisations and their HRs is critical, particularly in challenging economic, political and social environments such as war-torn areas and during natural disasters. They continue thatThese organisations encompass an enormous range of organisations including community sport and recreational clubs, community service organisations, industry associations, social movements, charitable organisations, religious organisations and emergency service organisations. The nature, operations, capacity and clientele of each of these organisations and the subsequent use of HRM will differ depending on organisation, environmental context and scope of international operations. Many of these organisations are multinational in nature spanning operations around the globe. However, the one constant is the critical importance of HRs both in terms of their ability to impact the levels of participation and the management of scarce resources within these organizations [14].

Soliman and Spooner believe that the successful implementation of new technologies is dependent on many factors including the efficient management of human resources. Furthermore, recent research indicates that intellectual assets and resources can be utilised much more efficiently and effectively if organisations apply knowledge management techniques for leveraging their human resources and enhancing their personnel management. The human resources departments are well positioned to ensure the success of knowledge management programs, which are directed at capturing, using and re-using employees' knowledge. Through human resources management a culture that encourages the free flow of knowledge for meeting organisational goals can be created [15].

Strategic human resource management technology effect and implication for distance... (Khalil Alsaadat) 


\subsection{Technology effect on human resource management}

Millar, et al contend that developments in ICT have had an impact on work practices within organisations and hence HRM. Digitization of work enabled individuals to connect to each other from one location to another and enabled the outsourcing of production formerly done in one location to a dispersed set of global locations. In HRM research and practice this has been accompanied by increasing attention to questions of how to compete globally while operating effectively within local cultures. Furthermore, the increasing availability of information networks has made possible largely virtual organizations. Where much of the communication is virtual, and where much of the work involves processing of information by knowledge professionals distributed worldwide, on behalf of clients who may themselves be globally distributed. This in turn has led to increased HRM demands within businesses to develop skills such as managing virtual teams [16].They also discussed the interaction of leadership and knowledge management with technology, they see that a more recent consideration for leaders of knowledge professionals is the introduction of technological methods for managing knowledge exchange. Such forms of technological knowledge management are designed to capture both explicit, or documented knowledge through the documentation of knowledge in an organisational repository, and implicit, or undocumented knowledge, through the development of databases, or knowledge maps which are designed to replicate social networks. These systems are developed in order to facilitate the access to and exchange of knowledge across an organisation and are often seen by organisational leaders as facilitating knowledge sharing across the organisation, speeding up the process and improving quality [16]. They concluded that developments in information and knowledge management technologies that are a global phenomena provide both the context for, and are a major driver and facilitator of strategies through which knowledge intensive organisations compete and prosper. The HRM implications of this are similarly global and given that larger percentages of the workforce are now working in knowledge-intensive professions, organisations or departments, the paucity of research on HRM in knowledge organisations urgently needs redressing [16].

Information technology has the capability to assist in both codification and personalization processes of organizational knowledge management. Employees can input and make accessible their specific knowledge such as job processes, checklists, and formal or informal work procedures through a variety of methods including blogs and wikis to share their stories and narratives. With the development of AI technologies, machine learning and deep learning algorithms have increased the quality of data mining. Using a data analytic system supported by deep learning, the machine can improve on the quality of information by encouraging learning through self-teaching. This learning can occur through user feedback, such as rejections, and get better every time when there is an interaction between the learner and the system [17]. Also personalized live discussion forum is a tool that can guide in analyzing, evaluating, displaying and sharing information among employees [18].

\subsection{Implications for distance training and learning}

Technological development have altered the way we communicate, learn, think, share and spread information [19]. The e-learning system, which is an information system, is often associated with human resources and can be seen as a strategic tool for organizations. The benefits to introduce e learning system include, higher employee satisfaction, better opportunities for career growth and flexible learning for employees, increased innovation, better operational efficiency and cost savings. These benefits help organizations obtain outstanding employees, more efficient business procedures, and lower costs. Liu, Huang and Lin indicated in their study that two research streams have been studied [20]. One stream focused on case studies which presented the processes and implications of introducing various ELS to enterprises, these studies demonstrated the difficulties enterprises encountered and how these difficulties were tackled. Another stream focused on identifying the CSFs for enterprises. For example, McPherson and Nunes conducted a focus group and revealed 66 CSFs divided into four clusters: leadership, structure and culture, design, technology and delivery. Sela and Sivan conducted twelve semistructured interviews and categorized CSFs into "must-have" and "nice-to-have." The former included useful and easy to use tools, marketing, management support, right organizational culture, and a real need for organizations. The latter included time to learn, support, mandatory learning, and incentives. These studies highlighted the key issues as a guideline when designing and implementing ELS [20].

Course management systems has been recognized as a tool of managing distance and e learning, Mcconachie et al, discussed this issue they argue that course management system have gone from small tools used by supposedly quirky staff members to dominant elements of higher education's information technology capability in less than a decade. Course management systems are software systems that are specifically designed and sold in the higher education market to educational institutions and society organizations to support teaching, learning and training that typically provide tools for communication, learners' and trainers' assessment, presentation of study material, and organization of learners and trainers activities. They also 
added Course management systems are but one part of the spectrum of information systems being implemented in contemporary institutions of higher education to support their operations. A chain of four more or less integrated systems were identified content creation tools; course management systems; student management systems; and accounting systems. Other authors have identified additional system types or used alternative labels such as Learning Content Management Systems, Enterprise Resource Planning systems, and Managed Learning Environments [21]. Human resource management and training of workers has become one of the key factors of company competitiveness within an economy which is informational and global. Massive incorporation by business of information and communication technologies (ICT) has changed production processes as well as business activity itself. Simultaneously, and in a reciprocal way, it has speeded up economic globalization processes. This broader penetration of ICT has entailed an increase in the use of knowledge as both a business input and output. This has, at the same time, led to a profound change in the conditions and characteristics of the labour market [22].

When an organisation consider and plan distance training, a variety of issues must be addressed if their online programs are to be successful. One major issue is faculty turnover, particularly among part-time, adjunct faculty. Faculty turnover is costly. This cost can involve course adaptation and redevelopment, faculty training, and increased staff support. In addition to being detrimental to an institution's budget, faculty turnover can also be damaging to its reputation. Institutions, therefore, should be proactive in developing a system focused on retaining high quality distance education faculty. Before an institution is capable of developing an effective distance education faculty retention system, factors that impact faculty participation in distance education and training must first be understood. In regards to situational aspects, Theall identified eight basic characteristics of human resource culture that motivate faculty to train: (1) a high level of administrative commitment and support; (2) faculty involvement, shared values, and a sense of ownership; (3) a broader definition of scholarship; (4) teaching and training demonstration or pedagogical colloquium as part of the hiring process; (5) frequent interaction, collaboration, and community among faculty; (6) a faculty development program or training center; (7) supportive and effective department chairs; and (8) a rigorous evaluation of teaching and training that is connected to tenure and promotion decisions [23].

\section{THE FIELD STUDY}

The purpose of the field study was to know the attitude of adult learners and employees towards distance training and learning and its effect on human resource management and development.

\subsection{Methods of the study}

A questionnaire was developed to be distributed among 105 adult employees from different government organizations in Riyadh, Saudi Arabia. The questionnaire contained items about the benefit of distance learning and training in developing and managing human resources, Also Statistical approaches was used and analyzed to reach the result of the field study. Correlation coefficient for five items of the questionnaires:

$\begin{array}{ll}1 . & .5447 \\ 2 . & .3747 \\ \text { 3. } & .4560 \\ \text { 4. } & .4237 \\ \text { 5. } & .4431\end{array}$

Reliability coefficients; Alpha $=.5703$

Frequencies and percentages for ten items of the questionnaires witch was given three levels agree, not sure don't agree as hsown in Table 1.

Table 1. Frequencies and Percentages for Ten Items of the Questionnaires

\begin{tabular}{cccccc}
\hline \multicolumn{2}{c}{ Don't agree } & \multicolumn{2}{c}{ Not sure } & \multicolumn{2}{c}{ Agree } \\
\hline Count & $\%$ & Count & $\%$ & Count & $\%$ \\
18 & 17.6 & 25 & 24.5 & 59 & 57.8 \\
16 & 16.0 & 39 & 39.0 & 45 & 45.0 \\
8 & 7.7 & 21 & 20.2 & 75 & 72.1 \\
5 & 5.0 & 27.0 & 68 & 68 & 68.0 \\
16 & 15.8 & 22 & 21.8 & 63 & 62.4 \\
\hline
\end{tabular}


Analysis of Variance was used to know if there are any significant differences among the sample of the study sample regarding ages between "20-25", "26-32", "32 and above", the result is as shown in Table 2.

Table 2. Analysis of Variance

\begin{tabular}{lccccc}
\hline \multicolumn{1}{c}{ Source } & D.F. & Sum of squares & Mean Squares & F ratio & F prob. \\
\hline Between & $(\mathrm{G}) 2$ & 29.0622 & 14.5311 & \multirow{2}{*}{1.1577} & .3183 \\
Within & $(\mathrm{G}) 101$ & 1267.6974 & 12.5515 & & \\
Total & 103 & 1296.7596 & & & \\
\hline
\end{tabular}

The analysis of variance showed that there were no significant differences among the sample of the study due to age category. T-test was used to know if there are any significant differences among the study sample regarding gender (male-female) the result of the $\mathrm{T}$ test is as shown in Table 3. T-test showed that that there were no significance differences among the sample of the study regarding gender category.

Table 3. Significant Differences among the Study Sample Regarding Gender (Male-Female) the Result of the T Test

\begin{tabular}{lcccccc}
\hline Variables & $\begin{array}{c}\text { Number } \\
\text { of cases }\end{array}$ & Mean & SD & SE of Mean & T value & 2-Tailed sig \\
\hline Male & 45 & 25.5556 & 3.101 & .462 & 1.47 & .144 \\
Female & 60 & 24.5333 & 3.798 & .490 & \\
\hline
\end{tabular}

\section{RESULT AND DISCUSSION}

The result of the study showed that most of the employees agreed that distance training and learning has a great effect on providing employees with skills and work knowledge which would reflect positively on human resource management. The result showed there is no significant deferences on the employees responds regarding age and gender. Workforce is currently more intrigued by the capacity to use online networking to encourage engagement with course material and to support the learning procedure [24].

The importance of online training is primarily because of the need for organizations to respond to rapid and continuous change in the organization's external environment and their human resource needs. Also the need for ongoing employee training requires a training and learning environment that makes it possible to progress professionally and, at the same time, to acquire general and firm-specific skills and new competencies. The training environment that favors direct linking with real labor experience is training in the workplace [22]. Online human resources training is a form of online training that uses computer network technologies to organize, develop, manage, and administer inservice training. If online human resource training programs are well designed, they can broaden the range of training opportunities and reduce the costs of providing retraining opportunities to employees by adopting information technology, and sharing educational resources. Research and case studies show that online training via the Internet provides an opportunity to develop new learning experiences for trainers by managing self-directed learning and training, and sharing information and ideas in a cooperative and collaborative manner [25].

Esterhuizen, et al, are of the opinion that the emerging pedagogical consensus is that constructivism is the most preferred and effective way of using online training technology in order to support trainers and learners during collaboration, authentic tasks, reflection, and dialogue. Faculty that employ traditional and training and learning styles may view training and learning technology as less appropriate and feel less positive about using TEL than those who believe in trainers centered approaches. In an effort to supplement or replace live contact training and learning, technology mediated distance learning frequently replicates the activities of face-to-face classrooms. Interactive technologies, like IWBs, are consequently employed to present one way presentations to trainers in remote locations, thus furthering instructivist pedagogy. The most valuable activity in a classroom of any kind is the opportunity for train to work and learn together [26].

Busquets and Bernal noted that Massive incorporation of knowledge into business activity and increasing labour market malleability has, in recent decades, led to a generalized increase in the need for continuous vocational training. The entirety of training activities developed by companies, workers, or their representing organizations must be directed to improving the professional competencies and skills of active workers, so that they may face the needs of a changing and digitalized global reality [22]. Up on the result and discussion the researcher provides the following model for distance learning and training programs in Figure 1. 


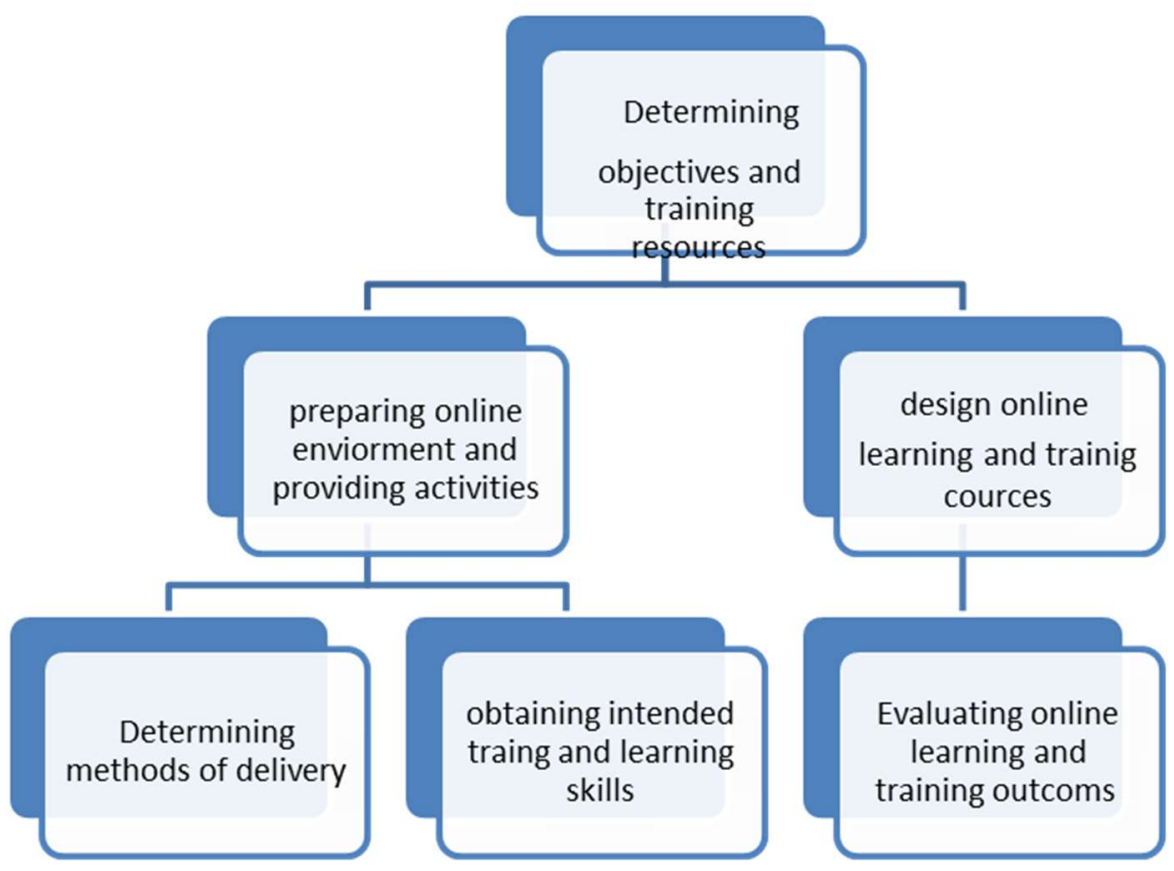

Figure 1. Model for distance learning and training programs

\section{CONCLUSION}

The multilevel nature of research in the field of HRM demands a significant emphasis on understanding cross level linkages between key predictors and outcomes [10]. Strategic planning presents great challenges and opportunities for HR professionals. Nearly all HR leaders in the largest global companies are involved in strategic decision-making and participate on the organization's strategy team, and a majority of HR professionals report that strategic planning is part of their function. In contrast, HR professionals in many medium and small organizations are not often involved in organizational or functional strategic planning. Consequently, to achieve long-term strategic HR objectives and to be a key player in the organization's strategic planning process, some HR departments may need to overcome stereotypical negative views of the HR function [1].

\section{ACKNOWLEDGMENT}

This is a research project that was supported by a grant from the research center for college of education, deanship of scientific research at King Saud University.

\section{REFERENCES}

[1] SHRM, oct, Practicing Strategic Human Resource, Society for Human Resource Management. www.shrm.org, 2015.

[2] Jackson.susan E, Schuler Randall S and Jiang Kaifeng, "An Asprational Frame Work for Strategic Human Resource Management," Academy of Management Annals, vol. 8, issue 1, 2014.

[3] Oppong, Nana Yaw \& Nisar Taher, "Exploring the Importance of Human Resource Activities Strategies Alignments: Interactive Brainstorming Groups Approach," Cognet Business and Management, vol. 4, issue 1, 2017.

[4] Marler, Janet H, Parry, Emma, "Human Resource Management, Strategicinvolvement and e-HRM Technology," The International Journal of Human Resource Management, vol. 29, issue 19, 2016.

[5] Ericksen Jeff \& Dyer Lee, "Toward a Strategic Human Resourcemanagement Model of High Reliability Organization Performance," The international journal of human resource management, vol. 16, issue 6, 2005.

[6] Kramar Robin, "Beyond Strategic Human Resource Management: Is Sustainable Human Resource Management The Next Approach?," The International Journal of Human Resource Management, vol. 25, issue 8, 2014.

[7] Amberg Joe J \& Mcgauaghey Sara L, "Strategic Human Resource Management and Inertia in the Corporate Entrepreneurship of a Multinational Enterprise," puplished on line 13, June 2016. http://dx.doi.org/10.1080/09585192.2016.1192051 
[8] Alfes, Kerstin, Antunes, bethania \& Shantz Amanda D, 2017, "The Management of Volunteers-What Can Human Resources Do? A Review and Research Agenda," The International Journal of Human Resource Management, vol. 28, issue 1, 2017.

[9] Armitage Andrew, "Is HRD in Need of an Ethics of Care?," Human Resource Development International, vol. 20, issue 4, 2017.

[10] Shen .jie, Messersmith.jack G, Jiang Kaifeng, "Advancing Human Resource Management Scholarship Through Multilevel Modeling," The International Journal of Human Resource Management, published online June, 17, http://dx.doi.org/10.1080/09585192.2017.1331622, 2017.

[11] Kowalski, Tina hp \& Loretto, Wendy, "Well-being and HRM in the Changing Workplace," The International Journal of Human Resource Management, vol. 28, no. 16. 2017.

[12] Taylor.Marcia \& Finley Dori, "Strategic Human Resource Management in U.S. Luxury Resorts-A Case Study," Journal Of Human Resource In Hospitality\&Tourisim, vol. 8, no. 1, 2008.

[13] Collins. Christopher J and Smith. Ken G, "Knowledge Exchange and Comination: The Role of Human Research Practices in the Performance of High Technology Firms," Academy of Management Annals, vol. 49, no. 3, 2006.

[14] Bartram, Timothy, Cavangh, Jillian \& Hoye Russell, "The Growing Importance of Human Resource Management in the NGO, Volunteer and Not-For-Profit Sectors," The International Journal of Human Resource Management, vol. 28 , no. $14,2017$.

[15] Soliman fawzy \&Spooner kerie, "Strategies for Implementing Knowledge Management: Role of Human Resources Management," Journal of Knowledge Management, vol. 4 no. 4, 2000.

[16] Millar.carla.J.M, Stephen. Chen\& Waller Lee, "Leadership, Knowledge and People in Knowledge-Intensive Organisations: Implications for HRM Theory and Practice," The International Journal of Human Resource Management, vol 28, no. 2, 2017.

[17] Li.Jessica\&Herd.ann M, "Shifting Practices in Digital Workplace Learning: An Integrated Approach to Learning, Knowledge Management, and Knowledge Sharing," Human Resource Development International, vol. 20, no. 3, 2017.

[18] Assgaff, setiawan, Kurniabudi, Hendri, "Social Media Success for Knowledge Sharing: Instrument Content Validation", International Journal of Electrical and Computer Engineering, vol. 6, no. 5, 2016.

[19] Alsaadat,khalil, "Mobile Learning Technologies", International Journal of Electrical and Computer Engineering, vol 7, no. 5, 2017.

[20] Ying Chieh Liu, Yu An Huang, and Chad Lin, "Organizational Factors' Effects on the Success of E-Learning Systems and Organizational Benefits: An Empirical Study in Taiwan," The International Review Of Research In Open And Distributed Learning, vol 13, no. 4. 2012.

[21] McConachie. jean , Patrick Alan Danaher_Jo Luck, and David Jones, "Central Queensland University's Course Management Systems: Accelerator or brake in engaging change," The International Review of Research in Open and Distributed Learning, vol. 6, no. 1, 2005.

[22] Busquets, Josep, Maria Batalla \& Bernal Carmen Pacheco, “On-the-Job E-Learning: Workers' Attitudes and Perceptions," The International Review of Research in Open and Distributed Learning, vol. 14, no. 1, 2013.

[23] Alejandro. Jeffery \& Brown. Abby, "The Retention of Experienced Faculty in Online Distance Education Programs: Understanding Factors that Impact their Involvement," The International Review of Research in Open and Distributed Learning, vol. 10, no. 3, 2009.

[24] Kumar, Sheth Tarik Mahendra, Singh, Santhosh Kumar, "A Review of Social Media: In Future," Indonesian Journal of Electrical Engineering and Computer Science, vol. 8, no. 3, 2017.

[25] Millar.carla.J.M, Stephen. Chen\& Waller Lee, "Leadership, Knowledge And People In Knowledge-Intensive Organisations: Implications For HRM Theory and Practice," The International Journal of Human Resource Management, vol. 28, no. 2., 2017.

[26] Esterhuizen, Hendrik Daniel, Blignaut Seugnet, and Ellis suria, "Looking Out and Looking In: Exploring a Case of Faculty Perceptions during E-Learning Staff Development," The International Review of Research In Open and Distributed Learning, vol. 14, no. 3, 2013. 